\title{
Knowledge, Practice, Attitude, Usability and Satisfaction Related to Existing Hospital Information System among Nurses
}

\author{
Navaneeta Kusum $^{1}$, Mini George ${ }^{2}$, Sarita $^{3}$ \\ ${ }^{1}$ M.Sc. Nursing, ${ }^{2}$ Principal, ${ }^{3}$ Assistant Professor, \\ College of Nursing, Institute of Liver and Biliary Sciences (ILBS), New Delhi
}

Corresponding Author: Navaneeta Kusum

\begin{abstract}
Introduction: Nurses represent the largest computer technology user group and using computer to enter patient's health history, documenting an assessment, physician's orders and access laboratory results ${ }^{[1]}$.

Methods: A descriptive cross-sectional study was conducted among the Nurses in Wards, ICUs and Emergency Department at ILBS, New Delhi. Total enumerative sampling technique was used to select 204 Nurses. Data was collected using Structured knowledge questionnaire, Practice checklist related to documentation, Likert attitude scale and Questionnaire for user Interface satisfaction to gather information about Knowledge, Practice, Attitude, Usability and Satisfaction related to existing HIS. Descriptive and Inferential statistics were used to analyse the data.

Results: Majority of the Nurses (80.3\%) had average Knowledge, with Duplication of work $(86.2 \%)$ in both HIS and paper records were found in Practice area. Total of 60.3 percent nurses had favourable attitude towards using existing HIS. Majority of Nurses reported that HIS was easy to use (>80\%), but not satisfied with the system as the computer never informs about its progress, unreliable and slow system speed frequently. Most of the Nurses (67.6\%) felt mistakes were difficult to correct in HIS.

Conclusion: Nurses had average knowledge with good documentation practice and favourable attitude related to HIS but least satisfied with the system speed. However, there were some duplication in documentation practice and dissatisfaction seen with the system among Nurses. HIS needs to review and update
\end{abstract}

regularly and informed to all stakeholders on a timely basis so that Usability of the system and the Satisfaction among nurses may increase.

Key words: Hospital Information System, EHR, EMR, Nursing Informatics.

\section{INTRODUCTION}

Hospital information systems (HIS) also known as Electronic Health record (EHR), Electronic Patient Record or Electronic Medical record has become one of the most important information technology in Healthcare setting.

Many large corporate hospitals had implemented HIS from the 1990s in India. This is due to the huge annual increase in the number of hospital beds, amount of clinical, administrative and financial data generated ${ }^{[2]}$. Information system in public healthcare is a relatively new concept in India. Ministry of Health and Family Welfare of India adopted the EHR in September 2013 for empowering the information infrastructure and significant contribution by pioneering e-Hospital in almost 30 major public hospitals across the Country including All India Institute of Medical Sciences, Dr. Ram Manohar Lohia in Delhi and National Institute of Mental Health and Neuro Sciences in Bangalore.

In healthcare organizations, Nurses are the main service providers who benefit directly or indirectly from HIS apart from the patients. Health experts believed that the 
ability of Nurses to utilize HIS effectively is significant to patient's wellbeing, reduced costs for training and decreased healthcare expenditures. However, Nurses required skills and knowledge to use HIS effectively and usually they gain knowledge through training and on job coaching ${ }^{[3]}$.

Use of HIS increases the speed of the daily routine workflow of Nurses. For Nurses, Documentation takes less time in HIS comparatively paper record and provide more opportunity to focus on bedside care of the patient. HIS enhances the communication and collaboration with the other department for delivering the patient care in terms of availability of centralized data.

\section{MATERIALS AND METHODS}

Research approach: Quantitative Approach

Research Design: Descriptive crosssectional study

Setting of the study: Wards, ICUs and Emergency Department at ILBS, New Delhi, India

Population: All registered Nurses using existing HIS at ILBS, New Delhi.

Sample: Registered Nurses using existing HIS in Wards, ICUs and Emergency Department of ILBS during 1st to 30th November 2018 \& directly providing care to the patient round the clock in three shifts a day.

Sampling technique: Total enumeration The size of the sample was estimated based on the following formula:

$$
\mathrm{n}=\frac{\left\{\mathrm{Z}_{1-\alpha / 2} \sqrt{\mathrm{P}_{0}\left(1-\mathrm{P}_{0}\right)}+\mathrm{Z}_{1-\beta} \sqrt{\mathrm{P}_{0}\left(1-\mathrm{P}_{0}\right)}\right\}^{2}}{\left(\mathrm{P}_{1}-\mathrm{P}_{0}\right)^{2}}
$$

Sample size: 204

\section{Selection criteria:}

Inclusion Criteria:

- All registered Nurses working in Wards, ICUs and Emergency Department of ILBS.

- Who were directly involved in the patient care and use HIS.

\section{Exclusion Criteria:}

- Nurses who were not willing to participate in the study.

- Who were on long leave during the data collection period.

- Who were not usually assigned to the unit where study was taking place.

Source of data: Data was collected from the Nurses working in Wards, ICUs \& Emergency Department of ILBS.

Tool for data collection: In the study, online survey questionnaires were used through Google Form administration app for collection of data. Four categories of tools were used such as Socio-Demographic Profile, Structured Knowledge Questionnaire, Likert Attitude Scale and Questionnaire for user Interface satisfaction (QUIS)

Methods of data collection: The present study included the Nurses screening was done by using inclusion and exclusion criteria. Informed written consent was taken from Nurses. Data related to sociodemographic data, knowledge and usability related to HIS and attitude towards HIS among Nurses were collected using structured questionnaire.

\section{Statistical Methods}

The collected data were put into the SPSS software version 22. Data were analysed and interpreted using descriptive and inferential statistics for the study.

\section{RESULTS}

Sample characteristics of Nurses included Age, Gender, Professional Qualification, Job designation and Work Experience, acquaintance with the computer, Own PC/ Laptop, Training on 
Navaneeta Kusum et.al. Knowledge, practice, attitude, usability and satisfaction related to existing hospital information system among nurses

HIS, Learning of HIS, Acquaintance with the computer, Own PC/ Laptop, Training on
HIS, Learning of HIS, Duration of HIS use and the shift where more time to use HIS.

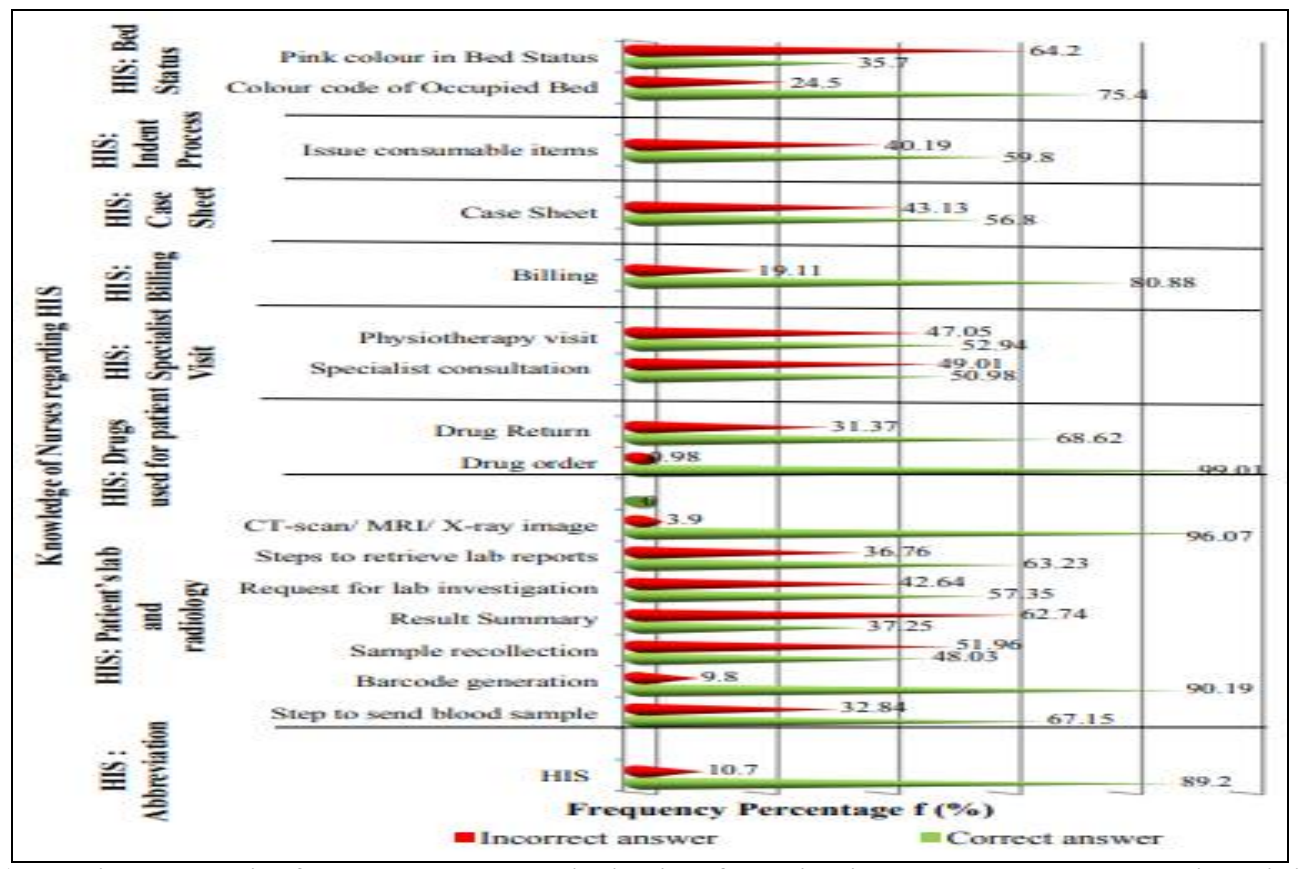

Figure 1: Bar diagram showing frequency percentage distribution of domain wise Nurses Knowledge regarding existing HIS

Figure 1 showed that the knowledge of HIS among nurses were more knowledge in the area of his abbreviation, generating barcode for labeling the blood samples, images of CT-scan/ MRI/ x-ray, order for patient medicine to the pharmacy, who were not involved in the billing charges of equipments. Less than half of nurses knowledge were seen to be less in what is the first step in sending blood sample, colour code for sample need to be collected again, request for any laboratory investigation, steps to retrieve laboratory reports, how to return the unused drugs to the pharmacy, specialist consultation, physiotherapy visit, access to patient's case sheet, indent process and identifying the colour code of bed status and result summary. Majority of the nurses $(80.3 \%)$ had only average knowledge and 10.7 percent nurses had poor knowledge. Good knowledge was seen in 8.8 percent only.

Figure 2 depicts that the documentation practice on both (HIS and
Paper record) was done in the practice of daily work routine of Nurses which was the duplication of the Nurses work in the area of requisition of blood component sent to the laboratory was reported by 94.1 percent of Nurses, $94.6 \%$ for Billing details of equipment, In-house transfer request (94.6\%), X-ray/ Barium studies and USG along with Blood/ Blood component request send by the Nurses to the respective area for the investigation $(>90 \%)$.

Documentation practice was still done on Paper record only not on HIS, it was reported by 98 percent of Nurses for the area such as medication error, nursing care plan $(98.5 \%)$, daily medications (99\%), intake output $(99.5 \%)$, vitals sign and allergic reaction (99\%). Majority of Nurses $(98.0 \%)$ reported that bed status was independently updated through HIS only. Nurses $(86.2 \%)$ had Good Practice, whereas only 1.4 percent of them had unsatisfactory level of documentation Practice in existing HIS. 
Navaneeta Kusum et.al. Knowledge, practice, attitude, usability and satisfaction related to existing hospital information system among nurses

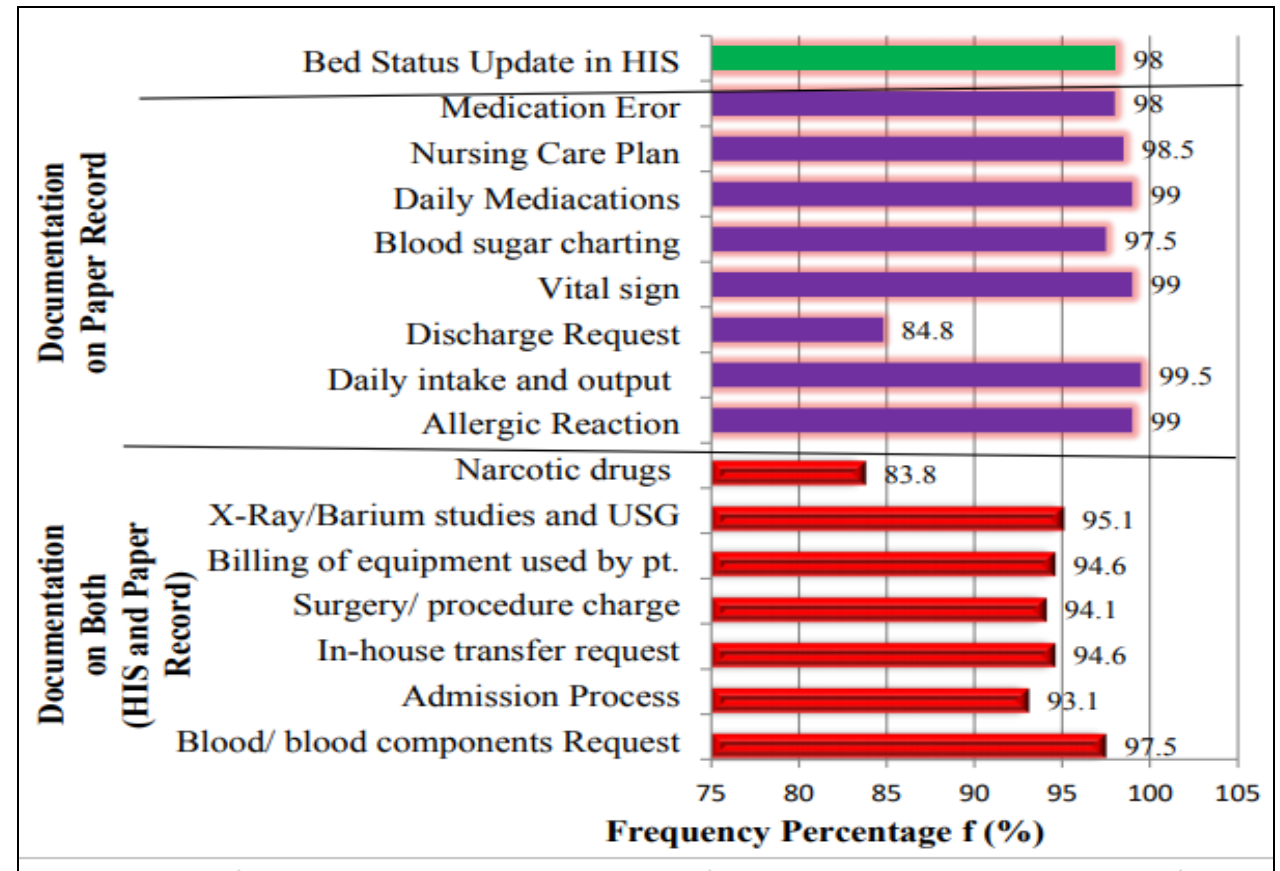

Figure 2: Bar diagram showing Frequency and percentag edistribution of domain wise Nurses practice of HIS documentation

Table 1: Frequency and percentage distribution of Nurses Attitude to HIS usage n=204
\begin{tabular}{|c|c|c|c|}
\hline Attitude Score & $\begin{array}{c}\text { Favourable Attitude } \\
\mathbf{f}(\boldsymbol{\%})\end{array}$ & $\begin{array}{c}\text { Neutral Attitude } \\
\mathbf{f}(\boldsymbol{\%})\end{array}$ & $\begin{array}{c}\text { Unfavourable Attitude } \\
\mathbf{f}(\boldsymbol{\%})\end{array}$ \\
\hline Overall & $123(60.3)$ & $72(35.3)$ & $9(4.4)$ \\
\hline
\end{tabular}

The data shown in the Table 1 depicts that most of the Nurses $(60.3 \%)$ had favourable attitude and only few of them
(4.4\%) had Unfavourable attitude towards using existing HIS.

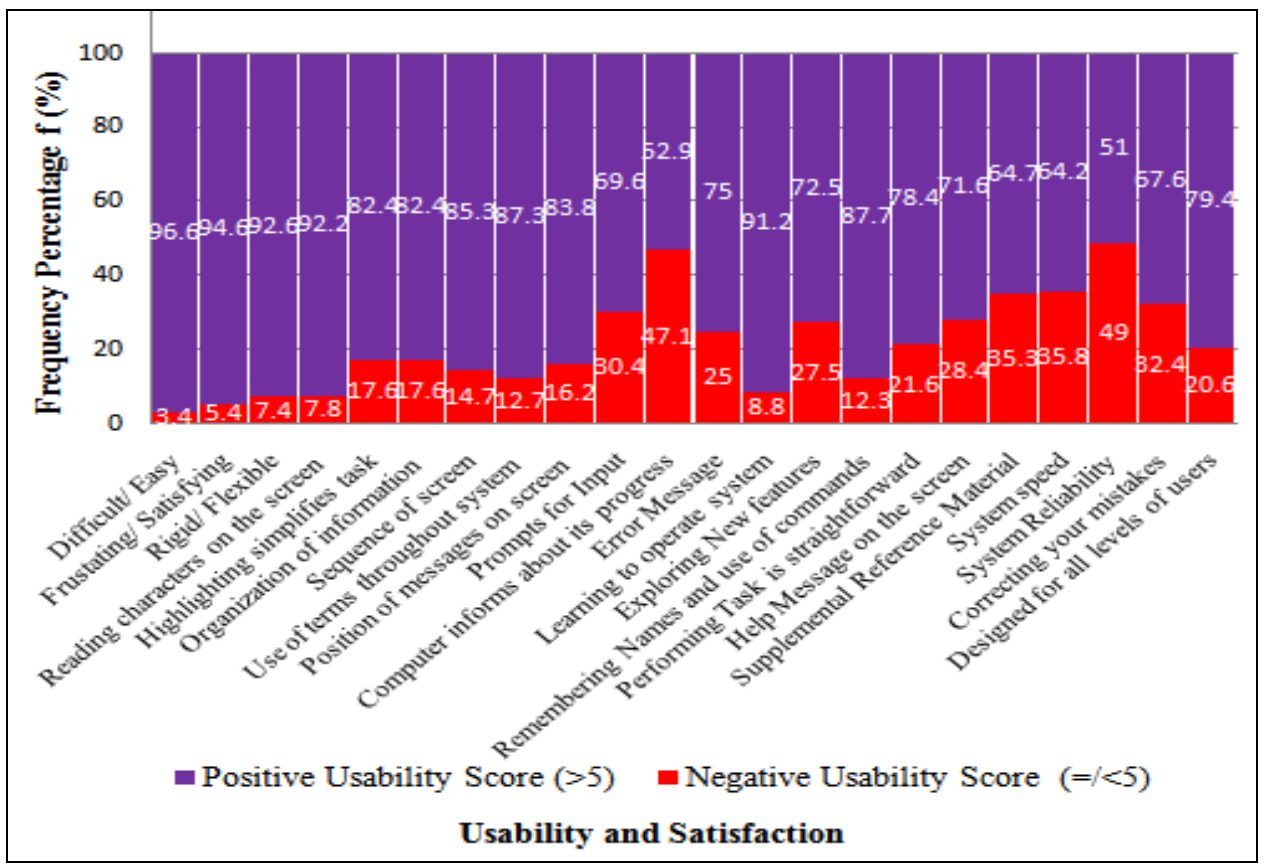

Figure 3: Stacked Bar diagram showing Frequency and percentage distribution of domain wise Usability and Satisfaction regarding existing HIS among Nurses

In the Stacked bar diagram (Figure 3), majority of Nurses reported that HIS is easy to use $(96.6 \%)$, HIS was flexible
$(92.6 \%)$, reading characters on screen was easy (92.6\%), highlighting simplifies task $(92.2 \%)$, learning to operate the system was 
Navaneeta Kusum et.al. Knowledge, practice, attitude, usability and satisfaction related to existing hospital information system among nurses

easy $(91.2 \%)$, remembering names and use of commands $(87.7 \%)$, use of terms throughout system were consistent $(87.3 \%)$, organization of information were clear $(85.3 \%)$, position of messages on screen were consistent $(83.8 \%)$, sequence of screens were clear $(83.3 \%)$, but nurses $(94.6 \%)$ were not satisfied with system as it was not designed for all levels users (79.4\%), computer never performs tasks straightforward (78.4\%), help messages on the screen was unhelpful $(71.6 \%)$, error messages always come (75\%), prompts for input was confusing $(69.6 \%)$, correcting the mistakes were not easy (67.6\%), supplemental reference materials was not clear $(64.7 \%)$, computer never inform about its progress $(52.9 \%)$, system was not reliable (51\%) and the system speed was too slow $(64.2 \%)$.

Figure 4 showed a negative correlation $(r=-0.320)$ between knowledge with Usability and Satisfaction, which was highly significant $(\mathrm{p}=.000)$. It means the knowledge of Nurses was adequate but the Usability of HIS and Satisfaction of Nurses was less.

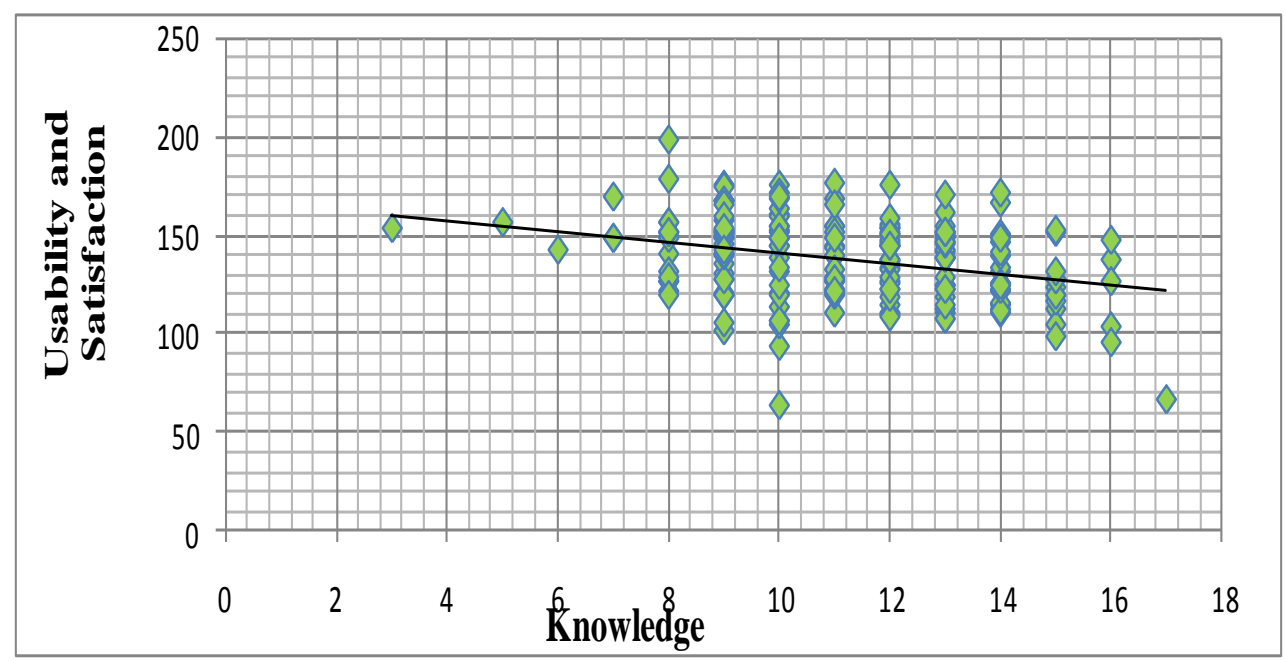

Figure 4: Scatter plot showing relationship between Knowledge and QUIS among Nurses using existing HIS.

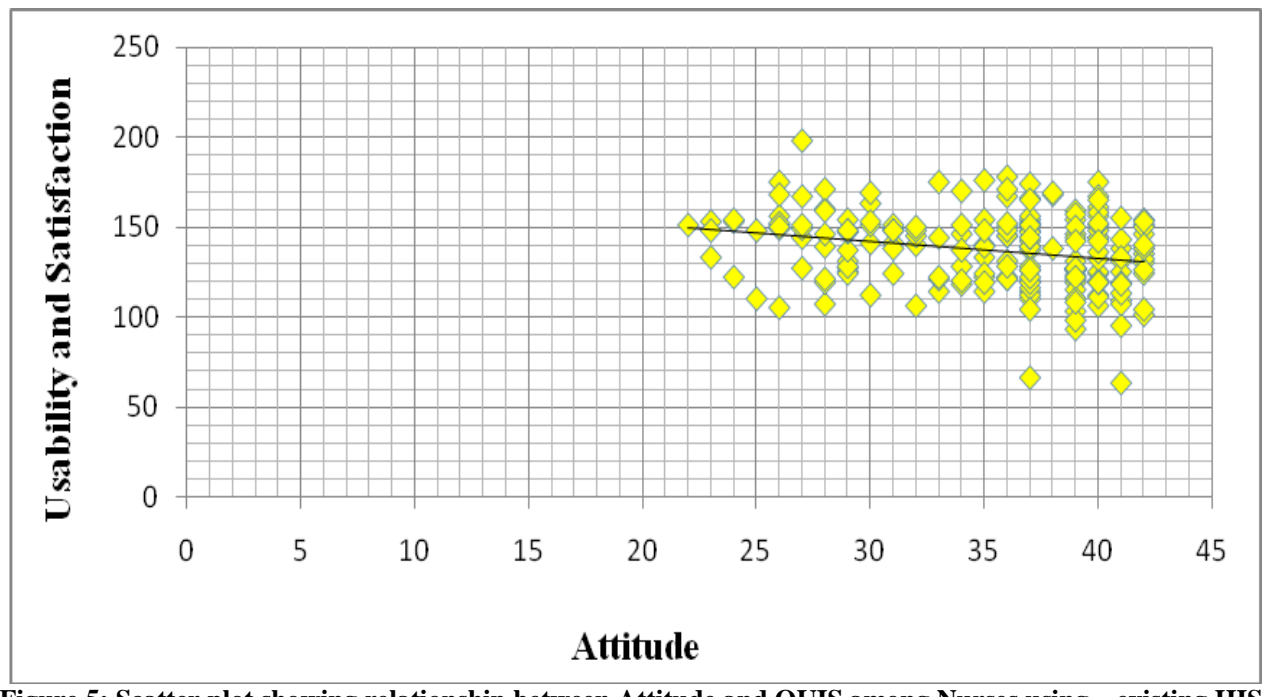

Figure 5: Scatter plot showing relationship between Attitude and QUIS among Nurses using existing HIS.

Figure 5 represents the attitude with Usability and Satisfaction was also negatively significant correlated $(\mathrm{r}=-0.243$, $p=0.00$ ) showed that the Nurses had favourable attitude of using HIS but the Usability of HIS and Satisfaction among Nurses was less. 
Post Hoc analysis was done and found the mean significant difference between acquainted with the computer meaning Nurses who were very well, well and comfortable with the computer were likely to be more knowledgeable of HIS.

Work experience was significantly associated with Usability and Satisfaction. Hence, the Nurses with more work experience had more satisfaction towards HIS use.

A significant mean difference was found in learning of HIS from colleague and IT-training. Therefore, Nurses learnt the HIS from Colleague and IT- training was more satisfied.

\section{DISCUSSION}

In the present study, majority of the Nurses $(80.3 \%)$ had average knowledge regarding existing HIS. However, majority of the Nurses $(98.0 \%)$ had good knowledge of the HIS ${ }^{[4]}$.

As for Practice of documentation in HIS, majority of the Nurses $(86.2 \%)$ were doing Good Practice, whereas only 1.4 percent of them had unsatisfactory level of documentation Practice. On other hand dissimilar kind of study revealed that more than half of the Nurses $(54.7 \%)$ had satisfactory level of Nursing care Practice [4].

Findings related to attitude of Nurses were found that most of the Nurses $(60.3 \%)$ had favourable attitude towards using existing HIS. In the context of attitude, similar findings were generalised in a study where it was found that 76 percent Nurses indicated the positive attitude towards using HIS. ${ }^{[5]}$

In the context of usability and satisfaction, majority of Nurses (94.6\%) were not satisfied with system. As the system speed was very slow frequently, less reliable $(51 \%)$ and not designed for all levels users $(79.4 \%)$. Similarly, 83 percent Nurses were not satisfied with the slow speed of system and not prepared to switch an alternative manual system in case the electronic system failed. ${ }^{[6]}$
Nurses (64\%) were reported that they perceived system barrier such as frequent downtime of HIS affects the user satisfaction. It was found that frequent slowdown of system speed affect the quality care of patient leads to decreases the satisfaction of Nurses. ${ }^{[5]}$

\section{ADDITIONAL FINDINGS}

It was found that a significant negative correlation $(\mathrm{p}=.001, \mathrm{r}=-.320)$ between knowledge with usability and satisfaction. It revealed that the nurses had adequate knowledge but the usability and satisfaction was less. These system deficiencies affected the usability and satisfaction of Nurses. Similar findings were revealed in a study in which Nurses (25\%) had good knowledge of HIS but they were moderately satisfied with system (mean score=3.28, $\mathrm{SD}=0.651)$. There were multiple challenges faced by more than 70 percent of Nurses reported slow network as a major technical challenge, poor system integrity, difficulty in accessing data, unavailability of user guidance and the complex design of the HIS ${ }^{[7]}$.

Similarly, a significant negative correlation $(\mathrm{r}=-.243, \mathrm{p}=.001)$ between Attitude with Usability and satisfaction was seen. The study showed that the Nurses had favourable attitude but they were less satisfied with the system. Which decreases the usability of the existing HIS. Similarly, user $(75 \%)$ were not satisfied with HIS content, messages, reference materials and timely IT support ${ }^{[8]}$.

Furthermore, mean significant difference was found between acquaintance with the computer and the knowledge. It reports that the Nurses, who are very well $(\mathrm{MD}=-5.3059, \mathrm{p}=.097)$ well $(\mathrm{MD}=2.2997$, $\mathrm{p}=.751)$ and comfortable $(\mathrm{MD}=42.0976, \mathrm{p}=$ 0.001 ) with the computer were likely to be more knowledgeable of HIS. Similarly, the basic knowledge of computer increases the Knowledge of HIS ${ }^{[7]}$. 


\section{IMPLICATIONS OF THE STUDY}

The findings of the present study have implication in various fields such as nursing practice, nursing administration, nursing education and nursing research.

\section{NURSING PRACTICE}

- Nurses must use the HIS for documentation in their practice area to increase the paperless system.

- HIS must be updated timely to enhance the quality of Nursing care to patient.

- Nurses are the end user of the HIS must be screen for their satisfaction with the HIS.

- IT training session should be provided to the Nurses during induction training to enhance their knowledge.

\section{NURSING ADMINISTRATION}

- A standard protocol must be established for the HIS training program for all Nurses.

- Nursing user manual should be updated with HIS.

- Ensures ongoing service education for Nurses to promote and enhance the practical skill of HIS.

\section{NURSING EDUCATION}

- Nursing students must be taught in their theory as well as practical about the HIS use.

- Nurse educator must conduct the IT training program for the Nurses.

- Nurse educator must ensures the HIS hands on practice session by the IT training.

\section{NURSING RESEARCH}

- An experimental study can be conducted to assess the effectiveness of HIS training program.

- A comparative study can be conducted to compare the Nurses level of satisfaction using HIS.

- A comparative study can be conducted to compare the effectiveness of in- service education of ILBS with other selected hospital.

\section{LIMITATIONS OF THE STUDY}

- During data collection period, researcher found difficulty to deal with the basic mobile phone user (no smart phone and email id).

- Few Nurses excluded from the study due to incorrect mobile number and email id.

\section{RECOMMENDATIONS}

- The study can be replicated by using large sample size.

- Interventional study can be conducted to compare the Nurses level of satisfaction using HIS after in-service education program.

- The study can be conducted to assess the level of acceptance of HIS and barriers (individual, organizational and environmental) associated with HIS.

\section{CONCLUSION}

The researcher concluded that most of the Nurses were Female, aged group between 25-35 years, qualified with General Nursing Midwifery qualification. Designations of the nurses were Patient Care Executive with more than eight years of working experience. Nurses were well acquainted with the computer and got training on HIS through IT training. Nurses felt that HIS was easy to use at Night shift.

Even though, the duplication of work in documentation practice on bothHIS and paper record was found. Still Nurses had favourable attitude towards using existing HIS.

Nurses revealed that HIS was flexible and easy to use, but not satisfied with system speed and reliability.

Acknowledgement: None

Conflict of Interest: None

Source of Funding: None

Ethical Approval: Approved 
Navaneeta Kusum et.al. Knowledge, practice, attitude, usability and satisfaction related to existing hospital information system among nurses

\section{REFERENCES}

1. Lee TT. Nurses' adoption of technology: application of Rogers' innovation-diffusion model. Applied Nursing Research. 2004 Nov 1; 17(4):231-8.

2. Korgaonkar RB. Adoption of information system by Indian hospitals; challenges and roadmap. Int J Sci Eng Res. 2014 Feb; 5(02):473-9.

3. Hughes R, editor. Patient safety and quality: An evidence-based handbook for nurses.

4. Ebrahem R, El-Din S, Habib N, Abou El Kheir S. Nurses' Knowledge, Attitude and Practices of Nursing Informatics System in Outpatient Clinics of Children's Cancer Hospital (57357) at Cairo. Journal of Education and Practice. 2014; 5(32):88-96.

5. Moody LE, Slocumb E, Berg B, Jackson D. Electronic health records documentation in nursing: nurses' perceptions, attitudes, and preferences. CIN: Computers, Informatics, Nursing. 2004 Nov 1; 22(6):337-44.
6. Khalifa M, Alswailem O. Hospital information systems (HIS) acceptance and satisfaction: a case study of a tertiary care hospital. Procedia Computer Science. 2015 Jan 1; 63:198-204.

7. Sinha RK, Kurian S. Assessment of end user satisfaction of hospital information system informatic Al Spitalului. Management in health. 2014 Jun 10; 18(3).

8. Nour El Din MM. Physicians' use of and attitudes toward electronic medical record system implemented at a teaching hospital in Saudi Arabia. The Journal of the Egyptian Public Health Association. 2007 Jan 1; 82(5-6):347-64.

How to cite this article: Kusum N, George M, Sarita. Knowledge, practice, attitude, usability and satisfaction related to existing hospital information system among nurses. International Journal of Science \& Healthcare Research. 2021; 6(2): 62-69. DOI: https://doi.org/ 10.52403/ijshr.20210413 